\title{
THE HISTORY AND CURRENT STATUS OF SURGERY IN THE TREATMENT OF LARYNGEAL CANCER
}

\author{
Aleš Čoček \\ Charles University in Prague, $3^{\text {rd }}$ Medical Faculty, Prague, Czech Republic: ENT Clinic
}

\begin{abstract}
Summary: The roots of surgery of the larynx reach into the $19^{\text {th }}$ century. After the gaining of initial experiences, a period of radical surgery followed when most tumours were treated with a total laryngectomy. The middle of the $20^{\text {th }}$ century can be characterised as a period of partial laryngectomies. The mutilation of patients caused by a total laryngectomy was and is one of the main impulses that led to the development of the current phase - combined treatment (radiotherapy, systematic cytostatic chemotherapy, biological treatment, surgery as an emergency treatment). The aim is to treat carcinoma of the larynx without the actual removal of the larynx itself and with the same oncological results as would be reached in cases treated with a total laryngectomy. Despite the development of non-surgical methods, surgery of carcinoma of the larynx remains a significant part of the treatment protocol. This work covers the development of surgery of carcinoma of the larynx from a historical point of view; it also describes current types of operations and discusses the position of surgery in today's treatment algorithm.
\end{abstract}

Key words: Carcinoma of the larynx; Laryngectomy; Radiochemotherapy; Neck lymph node dissection

\section{History of the treatment of carcinoma of the larynx}

The development the treatment of carcinoma of the larynx is closely linked with the development of the diagnostics of this cancer.

Examination of the larynx was not always for granted. The indirect technique of examining the larynx with the aid of a dentistry mirror (1) was only developed by Manuel Garcia in the middle of the $19^{\text {th }}$ century. The first direct laryngoscopy was performed by Alfred Kirstein in 1895. It was not the examination performed with today's instruments and technology but it allowed a previously impossible direct look into the larynx (14).

Microscopic diagnosis of the illness was first described in the mid $19^{\text {th }}$ century by Virchow (26). Even so, many ill people continued to die from undiagnosed carcinoma of the larynx and several unnecessary laryngectomies were performed on patients with a false positive diagnosis of carcinoma of the larynx. An idea of the state of affairs at the end of the $19^{\text {th }}$ century is given by the example of the Prussian Crown Prince, late Emperor Frederick III of Germany. Despite the fact that his examinations and treatment were conducted by the top doctors of the time, led by Morell Mackenzie (22), who relied on Virchow's histological examination, Frederick died within two years due to an originally small tumour of the left vocal cord. Problems with stating a diagnosis, during which perichondritis of the cartilage of the larynx and syphilis were considered, as well as, delays in treatment and squabbles between the participating experts indirectly led to the development of world events. The death of the liberal Frederick, who dreamed of democracy, led to the government of Emperor William II., who led Germany into World War I.

Difficulties in differential diagnosis between carcinoma of the larynx, tuberculosis and syphilis were significantly reduced with the works of Koch who discovered the Koch bacillus in 1882 and by Wassermann, who introduced a test for syphilis in 1906. Until then otolaryngologists had to rely on their own clinical experience and often had to operate without a previous biopsy (21).

The development of the treatment of carcinoma of the larynx went through various stages (11). After an initial period of blundering and primary experiences, a period of radical surgical treatment began. The most common treatment of the time for carcinoma of the larynx was a total laryngectomy. In the next phase, doctors concentrated on saving the function of the larynx, especially the voice, while adhering to the principles of oncological safety and radicalism (the partial laryngectomy period). These principles have also been accepted by the current period and have been added to the effort to retain a functional larynx, even in cases of widespread tumours which would have to be treated surgically with a total laryngectomy (the combined 
treatment, larynx preservation protocol period). The main aim of these larynx preservation protocols is the use of a combination of systematic cytostatic chemotherapy, radiotherapy and eventually surgery. This period is far from over and will no doubt evolve further with the development of biological treatment (17).

\section{The period of radical surgery of carcinoma of the larynx (total laryngectomy)}

The idea of removing the entire larynx with the goal of removing a radically malignant tumour was alive in the first half of the $19^{\text {th }}$ century. However, there were too many barriers to performing the operation. Current anaesthesia was not available and neither was modern preoperational or post operational care - especially the possibility of transfusing blood and antibiotic therapy, not to mention the possibility of parenteral and modern enteral nourishment. Even at the end of the $19^{\text {th }}$ century, a total laryngectomy was a high risk operation and many sufferers died from infection, complications (especially bronchopneumonia, aspiration and sepsis) and haemorrhaging. The first total laryngectomy was performed in 1873 by Billroth, who removed the entire larynx and left the patient with a pharyngocutaneus fistula. The patient was discharged from the hospital into homecare but died seven months after the operation as a result of the progress of metastasis (12). According to literature, the first patient cured by a total laryngectomy was a sarcoma of the larynx sufferer who survived his operation performed in 1875 by Enrico Bottini by fifteen years (1).

The operation did not reach an acceptable risk level until the $20^{\text {th }}$ century due to developments in anaesthesia and post operational care. A breakthrough came in the introduction of the one-phase technique of separating the airway and the pharynx during the operation by sewing the trachea to the skin which prevented fatal aspirations. An one-phases operation, performed in a way similar to a current laryngectomy was described in 1890 by Sorenson, a student of Gluck (13). This operation only reached its maximum potential with modern RTG diagnostics (especially CT). This allowed the distinction between intra and extralaryngealy spreading forms of the tumour and the correct indication of a total laryngectomy from the so-called widefield (see below) improved treatment results.

A significant effect on treatment results was in the development of surgery of the neck lymph nodes. Even in 1847, Chelius stated that if a tumour of the head or neck is creating metastasis into the lymph node, it is impossible to control the disease (20). In 1906, Crile described the first standardised neck dissection of the neck lymph nodes (4). Further development in the strategy of treatment of the lymph nodes is associated mainly with the names of Martin, Bocca, Lindenberg, Shah, Medina (3). The result of this development is the current strategy of neck dissections which continues to develop and is still not standardised globally.

\section{The period of conservative surgery of carcinoma of the larynx (partial laryngectomy)}

Even though the beginnings of thyreotomy and partial laryngectomy date back roughly to the mid $19^{\text {th }}$ century (5), the era of partial laryngectomies can only be spoken of from the mid $20^{\text {th }}$ century. Until then, partial resections of the larynx were often oncologically unradical with common recurrences and both peroperational and post operational complications were significant, which was the reason why most tumours were treated with a total laryngectomy. Despite the effectiveness of a total laryngectomy, this radical operation was considered too extensive for small intralaryngeal tumours. The beginning to the partial laryngectomy period was allowed for by knowledge gained about the anatomy of the larynx, its individual compartments and lymphatic sourcing, which led to an understanding of the spreading of the tumour in the larynx and into the regional lymphatic system $(24,25)$. This enabled the development of surgery which allowed for the removal of a tumour with relatively small healthy margin while adhering to the principle of oncological radicalism and preserving the function of a quality larynx. The treatment results of these operations were comparable with the results of total laryngectomies performed in cases with the same indications. An essential condition of the beginning of the period of conservative surgery of the larynx was the development of general anaesthesia and post operational patient care.

From a historical point of view a thyreotomy with satisfactory results was only performed at the turn of the $19 / 20^{\text {th }}$ century. The first vertical laryngectomies were performed in the mid $19^{\text {th }}$ century but only began to develop as an onephase operation with defect reconstruction after the Second World War. An excellent technique of reconstruction was introduced by Sedláček (18), who described the reconstruction of a defect of a constricted epiglottis. This method is very quick, elegant and simple to perform. The first classical partial horizontal laryngectomy was described in the 1920's (23), the current technique is mainly associated with the name of Alonso, who developed this operation in the 1940's (2). The development of the period of conservative surgery is still ongoing and continues in the development of various subtotal operations whose use and spread is however limited due to various limitations, especially technical difficulty and results that are not always satisfactory when it comes to functionality. A more hopeful path for the development of partial resections of the larynx appears to lie in the use of transoral resection of larynx tumours with a $\mathrm{CO}_{2}$ laser through direct microlaryngoscopy. Indications for this operation are dependant on the experience of the surgeon with this technique and on the visibility of the operating field. While some supporters of laser surgery consider classical partial laryngectomy to be part of the past, others are more cautious in the indication of this technique (19). 


\section{The combined treatment period (larynx preservation protocols)}

Already at the beginning of the $20^{\text {th }}$ century, radiotherapy began to be talked about as an alternative treatment method for carcinoma of the larynx (8). While results of surgical treatment and radiotherapy can be comparable with early stage tumours, this cannot be said of advanced tumours where radical surgical treatment still holds its ground. Because total laryngectomy involves considerable mutilation of the sufferer, radiotherapy was preferred in many cases as a primary treatment despite the fact that the probability of healing the patient with a total laryngectomy and eventual post operational radiotherapy was higher. A total laryngectomy was kept in reserve in event of the failure of radiotherapy. A breakthrough work in the attempt to treat a widespread carcinoma of the larynx without its removal was a study published in 1991, known as the VA protocol (Veterans Affairs Laryngeal Cancer Study Group) (7). This prospective study compared two groups of patients. The first group was made up of patients with advanced carcinoma of the larynx who underwent a total laryngectomy with post operational actinotherapy. The second group consisted of patients who were subjected to two cycles of systematic cytostatic chemoterapy, and were exposed to radiation in the case of a positive response (Fig. 1). Comparison of the two groups showed that the probability of a five year survival rate was similar and that with $2 / 3$ of the nonsurgical group it was possible to save the larynx. The results of the VA study were later supported by the results of EORTC study (15). Another advance was gained by the RTOG 91-11 study (Fig. 2). It compared three groups of patients. The first group consisted of patients with advanced carcinoma of the larynx that was treated with independent radiotherapy. The second group was treated with concomitant radiochemotherapy with

1. group TLE

Radiotherapy

2. group

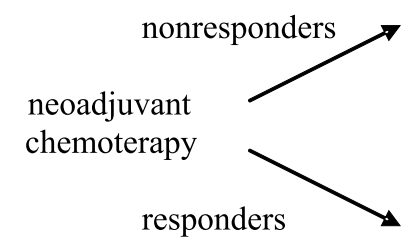

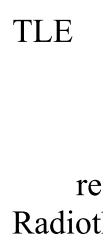

residual

complete response

Fig. 1: VA Cooperative Study: Treatment of operable laryngeal carcinoma (TLE - total laryngectomy).

1. arm Radiotherapy

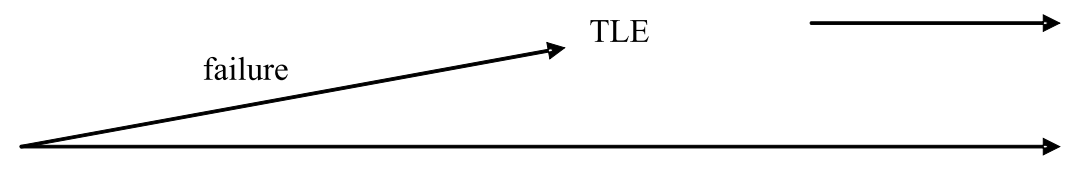

2. arm Radiochemotherapy (cis - platina)

failure TLE

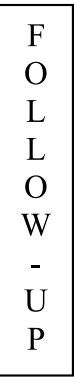

3. arm neoadjuvant chemotherapy (cis - platina and 5-FU) 2 cycles

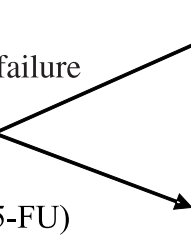
TLE

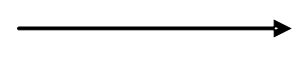

radiotherapy

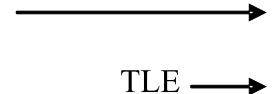

failure

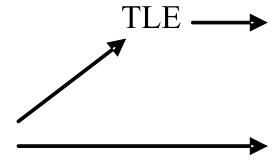

3. cycle chemotherapy

radiotherapy

Fig. 2: RTOG 91-11 Study (TLE - total laryngectomy). 
cisplatinum and the third group with two cycles of neoadjuvantive systematic chemotherapy with cisplatinum and 5-fluorouracyl. In cases of a positive response, a third cycle was administered and the treatment was then finished with radiotherapy. In the case of a negative response, a total laryngectomy was performed. The results of this study are comparable across all three groups,. The best results, in the sense of locoregional control and preservation of the larynx were among the concomitant radiochemotherapy group (9). At present, a large number of various studies are being conducted which compare further treatment combinations (preservation protocols) using various cytostatics, various actinotherapy regimes or in combination with modern biological treatment - in the head and neck tumour areas, ce-

\begin{tabular}{|l|}
\hline \multicolumn{1}{|c|}{ Partial Laryngectomy } \\
- Chordectomy \\
- Vertical Laryngectomy \\
- Horizontal Laryngectomy \\
- Subtotal Laryngectomy \\
\hline \multicolumn{1}{c|}{ Total Laryngectomy } \\
- Narrow Field Laryngectomy \\
- Wide Field Laryngectomy \\
\hline \multicolumn{1}{c|}{ Wide Spread Total Laryngectomy } \\
- Laryngectomy with Resection of the Sorrouding \\
Structures (Base of the Tongue, Pharynx, Thyroid \\
Gland ...) \\
\hline
\end{tabular}

Fig. 3: Types of laryngectomies.

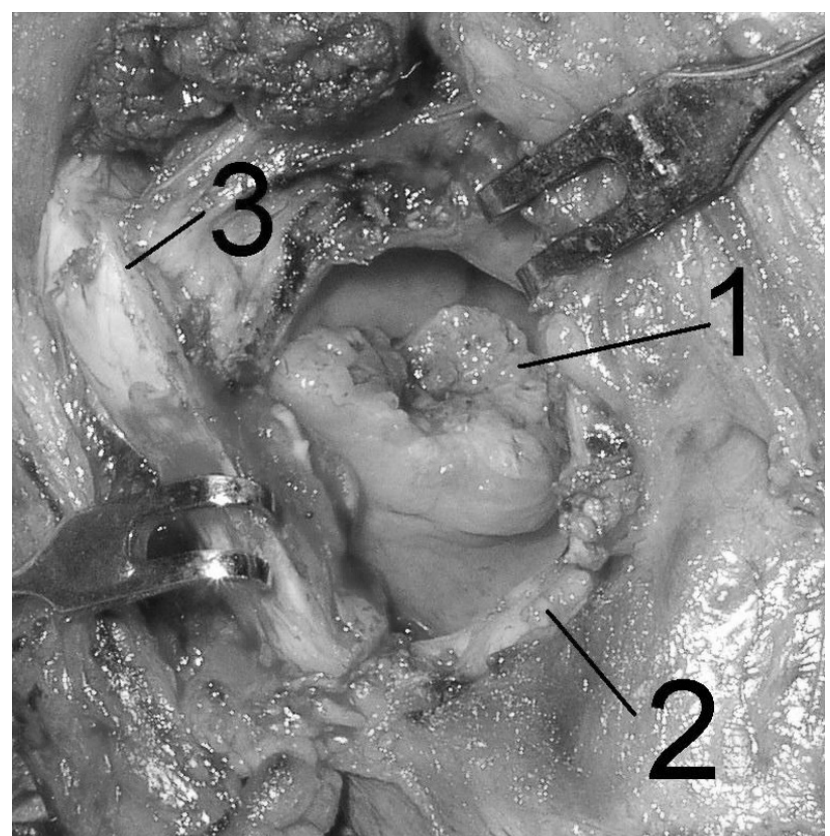

Fig. 4a: Partial vertical laryngectomy - cancer of left vocal cord with infiltration of ventriculus laryngis and subglotis ( 1 tumor, 2 upper margin of cricoid cartilage, 3 thyroid cartilage - cutted in midline). tuximab is mainly being tested (an EGFR blocker). The results of these studies are yet to be confirmed by large randomised studies.

\section{An overview of surgery of malignant tumours today (Fig. 2)}

\section{Thyreotomy with chordectomy (removal of the vocal cord)}

A chordectomy is an operation appropriate for a small tumour limited to a freely mobile vocal cord which does not reach the anterior commissure and ideally neither the vocal process of arytenoid cartilage. From the view point of classical surgery the operation can have various non-standard modifications (6). Thyreotomy as an approach to chordectomy is currently being replaced by direct laryngoscopy with removal of the vocal cord by $\mathrm{CO}_{2}$ laser. The main advantage of endoscopic laser resection under the control of a microscope lies in the absence of swelling of the resection areas, good control of bleeding and the possibility of reoperation. Most patients can avoid per-operational securing of the airways via a tracheostomy.

\section{Partial vertical laryngectomy (Fig. 4a,b)}

This operation is appropriate for tumours that are spreading from the vocal cord to the ventriculus laryngis, subglottis or to the anterior commissure. It is suitable for treating tumours that are infiltrating part of the contralateral vocal cord. Removal of the endolaryngeal tissues and the surrounding cartilage create a defect which it is necessary to reconstruct. At the clinic we use the already mentioned method of reconstruction into the constricted epiglottis according to Sedláček. Even a vertical laryngec-

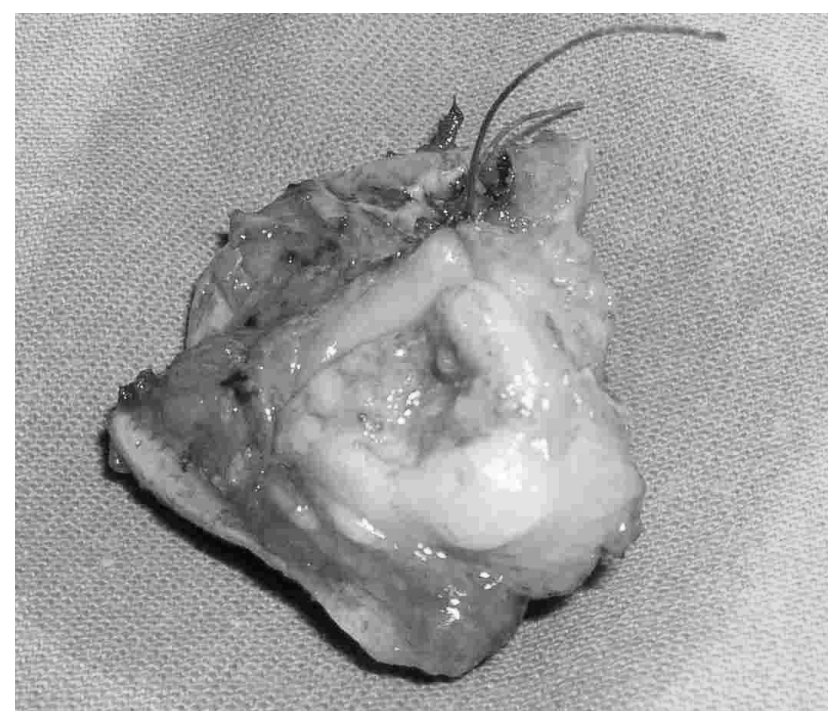

Fig. 4b: Specimen after resection (dorsal margin of tumor is marked). 
tomy has various modifications. This type of operation is being replaced by resection of the tumour through transoral $\mathrm{CO}_{2}$ laser in many, especially European clinics. However, the success of this approach is significantly affected by the surgeons experience with the method, especially in the case of infiltration of the cartilage by the tumour. In this case, even most supporters of endoscopic laser resection surgery would not refuse a classical partial vertical laryngectomy.

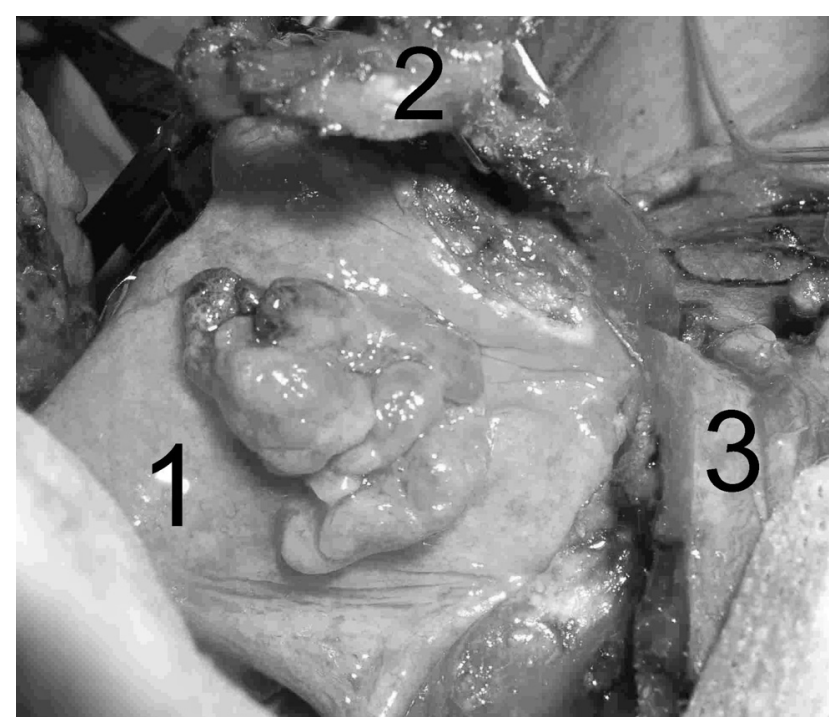

Fig. 5a: Parcial horizontal supraglotic laryngectomy - infiltration of the laryngeal surface of epiglottis (1 laryngeal surface of epiglottis with tumor, 2 hyoid bone and upper resected part of thyroid cartilage, 3 lower part of salvaged thyroid cartilage).

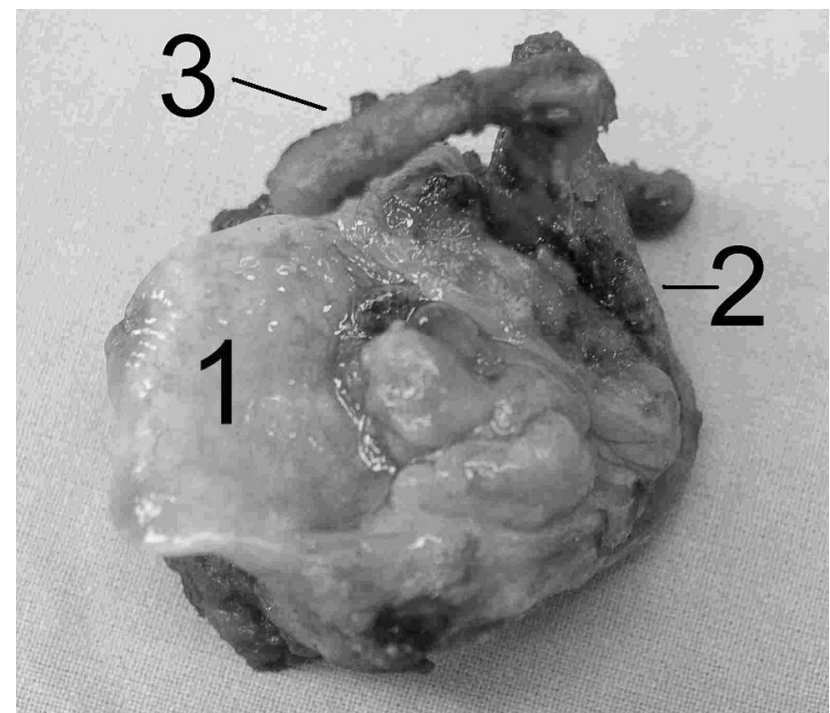

Fig. 5b: Specimen after resection - hyoid bone (3) and upper part of the thyroid cartilage (2) is visible (1 laryngeal surface of epiglottis with tumor).

\section{Partial horizontal supraglottic laryngectomy (Fig. 5a,b)}

Tumours of the supraglottic part of the larynx which have not spread to the glottis are the main indications for this operation. Another indication is carcinoma of the base of the tongue or small tumours of the hypopharynx, which are spreading to the supraglottis. The basis of the operation is to remove the entire supraglotic part of the larynx in-

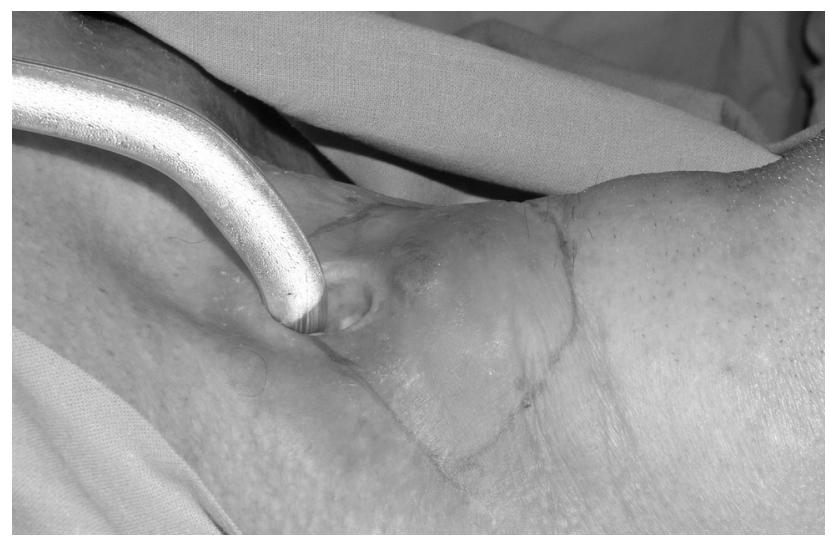

Fig. 6a: Cancer of larynx with infiltration of praelaryngeal soft tissue, preliminery acute tracheostomy is visible.

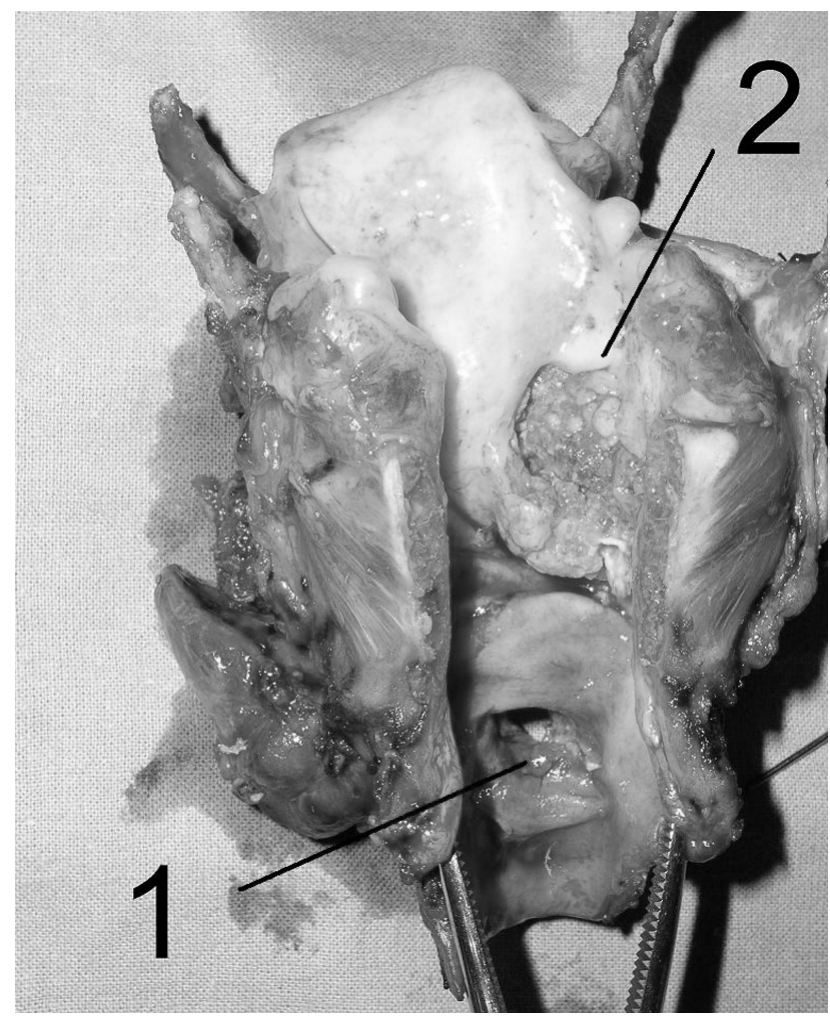

Fig. 6b: Specimen (whole larynx with tumor (2)) after resection - (1) preliminery tracheostomy is part of the resection. 


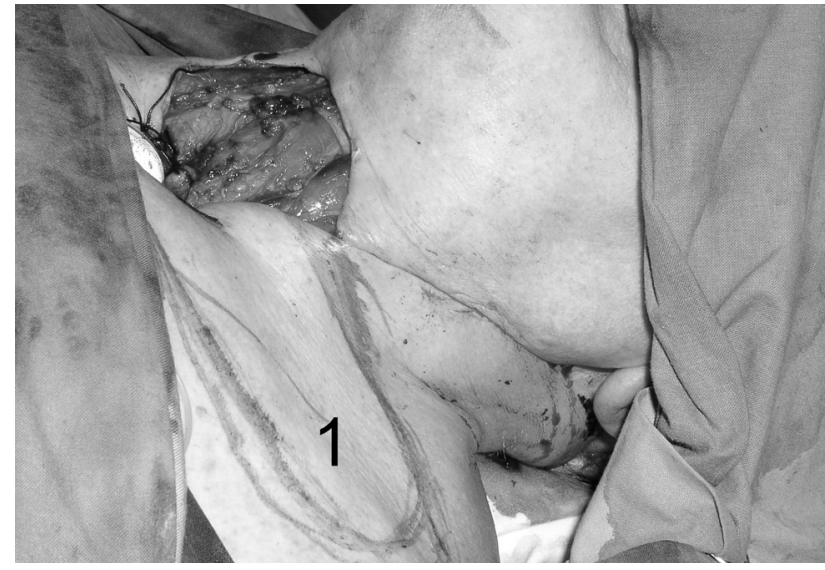

Fig. 6c: Reconstruction with deltopectoral flap (1 marked flap before elevation).

cluding the adjoining thyroid cartilage and the whole preepiglottic area, eventually with the surrounding tissue according to the spread of the tumour. In these cases, some clinics replace classic surgery with transoral endoscopic laser resection according to the experience of the surgeon. However, even here and especially with more widespread tumours, we can expect that the classic horizontal supraglottic laryngectomy still has significance.

\section{Total laryngectomy (Fig. 6a,b,c,d)}

Removal of the entire larynx is indicated in the case of a widespread larynx tumour which cannot be treated by a partial laryngectomy. Today, most total laryngectomies are done from the so-called widefield which means that prelaryngeal infrahyoid muscle tissue is removed together with the larynx. Very often, an ipsilateral hemithyreoidectomy is part of the total laryngectomy - especially in cases of carcinoma of the piriform sinus or subglotically spreading tumours. A laryngectomy can be added to by the resection of other structures - a total thyreoidectomy, resection of the base of tongue, partial or total pharyngectomy, cranial part of the oesophagus or trachea, soft prelaryngeal tissue including the skin etc. At the end of the operation the stump of the trachea is sutured to the skin (definitive tracheostomy) and the hypofarynx is closed with sutures so it is definitely separated from the airway. Although the number of total laryngectomies has decreased after the introduction of preservative protocols, this operation remains a method of choice with tumours that do not react to non-surgical treatment or relapse. A total laryngectomy is still irreplaceable as a primary treatment method in some cases.

\section{Subtotal laryngectomy}

The principle of a subtotal laryngectomy is in the removal of a tumour while retaining the rest of the larynx in the sense of a shunt between the airway and the hypopha-

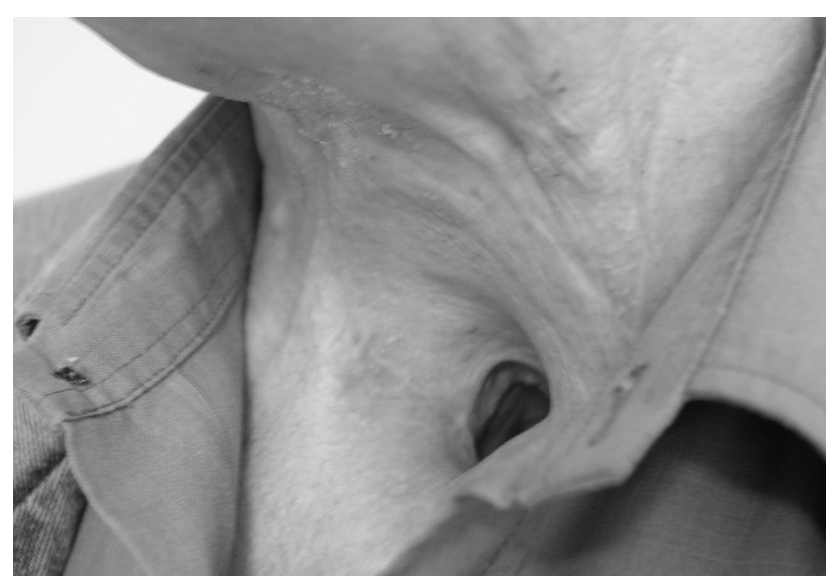

Fig. 6d: Patient 1 year after surgery.

rynx which allow the formation of the voice. A condition for this operation is the preservation of at least one functional cricoarytenoid joint. Many variations of these operations exist but they are rarely indicated. The reason is the already mentioned technical difficulty and common functional inadequacies of the larynx (mainly aspiration).

\section{Current treatment strategy - the position of surgery today}

The early stages of carcinoma of the larynx are mainly treated surgically. Partial laryngectomies can have excellent oncological and functional results in correctly indicated cases. The treatment time is shorter and the overall costs are lower than with actinotherapy and the potential risk of radiotheraphy induced secondary malignity is eliminated. In the case of infiltration of the cartilage structures of the larynx, surgical treatment results are considerable better than primary actinotherapy. An alternative method in the treatment of early carcinoma of the larynx is actinotherapy. In the case of failure, an emergency total laryngectomy is still an option and in some cases an emergency partial laryngectomy is also possible.

Today, advanced stages of laryngeal tumours earlier indicating a total laryngectomy are mainly treated with radiochemotherapy with the option of a total laryngectomy in case of failure of conservative treatment. The optimal approach, which would allow for the preservation of the larynx and the healing of the tumour, is still being sought by prospective randomised multicentric studies. Despite the advances, surgical treatment still cannot be dismissed. There are cases where radical surgery is still indicated as the primary treatment method, for example with an uncooperative patient, with carcinomas causing destruction the skeleton of the larynx or with retrocricoid tumours. Although so-called preservation protocols have saved the larynx of a large amount of sufferers, they also have their disadvantages. A preserved larynx is not always fully func- 
tional, it may be difficult to diagnose the recurrence or persistence of a tumour in a larynx changed by treatment, the risk of locoregional recurrence is higher than with the standard procedure of a total laryngectomy with post operational actinotherapy etc. Also, emergency laryngectomy in the case of failure of the preservation protocol carries a higher risk of postoperational complications than an operation in a previously untreated terrain. The main risk is in healing per secundam with the development of a pharyngocutaneous fistula (10).

Surgery still holds a significant place in the treatment of metastasis into the neck lymph nodes. In the case of operating a tumour with positive node metastasis a complete dissection of the lymph neck nodes is indicated. In the case of a negative node finding only a selective operation limited to the group nodes II-IV (nodes along the great neck vessels with a width in the range of $\mathrm{m}$. sternocleidomastoideus from the skull base to the clavicule) is indicated. The exception is small tumours of the glottis, where there is small probability of continued metastasis and therefore an elective (prophylactic) dissection of the neck lymph nodes is not indicated. One question is the neck dissection among patients who are being treated within a preservation protocol. In the case of a positive pre-treatment node finding, some authors recommend a neck lymph node dissection after the end of radiochemotherapy. Others believe that this operation is not necessary with complete regression of the node finding. (16).

Surgery still holds and will hold an important place in palliative treatment, especially in the sense of retaining the airway canal. However, it is also important to remember that any surgical palliative step is indicated only when it leads to the improvement of the quality of life for the patient.

\section{Conclusion}

Oncological surgery of the larynx has made considerable advances since the middle of the last century and further significant development is improbable. An equal advance has been made in the area of non-surgical treatment of carcinoma of the larynx. The results of preservative protocols in the treatment of advanced tumours are very hopeful and further advances can be reached by global prospective studies. The research of cancerous growth and the development of specific biological treatment, as well as the evolvement of radiotherapy apparatus strengthens the hope that the significance of wide scale mutilating operations for the treatment of carcinoma of the larynx will gradually decline and that treatment results will continue to improve.

\section{References}

1. Alberti PW. The evolution of laryngology and laryngectomy in the mid-19 $19^{\text {th }}$ century. Laryngoscope 1975;85:288-98.

2. Alonso JM. Partial horizontal laryngectomy. Functional or physiological operation for supraglotis cancer. Laryngoscope 1966;76:161-9.

3. Betka J. Př́íspěvek ke klasifikaci krčních uzlin a blokových disekcí. Otorinolaryngol. (Prague) 1996:45:73-77.

4. Crile G. Excision of cancer of the head and neck. J. Amer. Med. Assoc. 1906;47: 1780-1786.

5. Čoček A. Chirurgická léčba nádorů hlavy a krku - historie a současnost. Prakt. Lék. 2002;82: 92-5.

6. Čoček A. Chirurgická léčba karcinomu hrtanu. Prakt. Lék. 2005;85: 577-580.

7. The Department of Veterans Affairs Laryngeal Cancer Study Group. Induction chemotherapy plus radiation compared with surgery plus radiation in patients with advanced laryngeal cancer. N. Engl. J. Med. 1991;324:1685-90.

8. Finzi N. Untitled letter to Lancet. Lancet 1909;1:868.

9. Forastiere AA, Goepfert H, Maor M, et al. Concurrent chemotherapy and radiotherapy for organ preservation in advanced laryngeal cancer. N Engl J Med 2003;349:2091-8

10. Ganly I, Patel S, Matsuo J et al. Postoperative complications of salvage total laryngectomy. Cancer 2005;103:2073-81.

11. Genden EM, Ferlito A, Silver CE et al: Evolution of the management of laryngeal cancer. Oral Oncology 2007;43:431-9.

12. Gussenbauer C. Über die erste durch Th. Billroth am Menschen ausgeführte Kehlkopf-Extirpation und die Anwendung eines künstlichen Kehlkopfes. Arch. Klin. Chir. 1874;17:343-56.

13. Hollinger PH. A century of progres sof laryngectomies in the northern hemisphere. Laryngoscope 1975;85:322-331.

14. Kirstein A. Autoskopie des Larynx und der Trachea (Laryngoscopia directa, Euthyskopie, Besichtigung ohne Spiegel). Arch Laryngol Rhinol (Berl). 1895; 3:156-64

15. Lefebvre J., Chevalier D, Luboinski B et al. Larynx preservation in pyriform sinus cancer: preliminery results of a European Organization for Research and Treatment of Cancer phase III trial. EORTC Head and Neck Cancer Cooperative Group. J. Natl. Cancer Inst. 1996;88:890-9.

16. Pellitteri PK, Ferlito A, Rinaldo A, et al. Planned neck dissection following chemoradiotherapy for advanced head and neck cancer: is it necessary for all? Head Neck 2006;28:166-75.

17. Recker K. Targeting cancer. Heidelberg: Springer, 2006.

18. Sedláček K. Přední a laterální rekonstrukční laryngektomie se stažením epiglotis. Čs. Otolaryng. 1965;14:328-34.

19. Steiner W, Ambrosch P. Endoscopic laser surgery of the upper aerodigestive tract with special emphasis on cancer surgery. Stuttgart: Thieme, 2000.

20. Stell PM, Bowdler O. Surgery for Head and Neck Cancer. In: Snow GB, Clark JR Multimodality Therapy for Head and Neck Cancer. Thieme, 1992:23-4.

21. Stevenson RS, Guthrie D. A history of otolaryngology. Edinburg: Livingstone Ltd, 1949

22. Stevenson R.S. Morell Mackenzie, The Story of a Victorian Tragedy. London: Wiliam Heinemann, 1946

23. Trotter W. Principles and technique of the operative treatment of malignant disease of the mouth and pharynx. Lancet 1913;1075-81:1147-52.

24. Tucker GF. A histological Metod for the study of the spread of carcinoma within the larynx. Ann. Otol., 1961;70:910-21.

25. Tucker GF, Smith HR. A histological demonstration of the developnemt of laryngeal connective tissue compartments. Trans. Am. Acad. Ophtalmol. Otolaryngol. 1962;66:308-18.

26. Virchow RLK. Die Cellularpathologie in unrer Begründung auf physiologische und pathologische Bewebelehre. Berlin: Hirschwald, 1858.

\section{Corresponding author:}

Aleš Čoček, M.D., ENT Clinic, Charles University, $3^{\text {rd }}$ Medical Faculty, Prague,

Šrobárova 50, 10034 Praha 10, Czech Republic; e-mail: ales.cocek@seznam.cz 